\title{
Localization of 'Candidatus Liberibacter solanacearum' and Evidence for Surface Appendages in the Potato Psyllid Vector
}

\author{
J. M. Cicero, T. W. Fisher, and J. K. Brown
}

First, second, and third authors: School of Plant Sciences, 303 Forbes Bld., University of Arizona, Tucson 85721.

Current address of first author: Department of Entomology and Nematology, University of Florida, Gainesville 32611.

Accepted for publication 28 October 2015.

\begin{abstract}
Cicero, J. M., Fisher, T. W., and Brown, J. K. 2016. Localization of 'Candidatus Liberibacter solanacearum' and evidence for surface appendages in the potato psyllid vector. Phytopathology 106:142-154.

The potato psyllid Bactericera cockerelli is implicated as the vector of the causal agent of zebra chip of potato and vein-greening of tomato diseases. Until now, visual identification of bacteria in the genus 'Candidatus Liberibacter' has relied on direct imaging by light and electron microscopy without labeling, or with whole-organ fluorescence labeling only. In this study, aldehyde fixative followed by a coagulant fixative, was used to process adult psyllids for transmission electron microscopy (TEM) colloidal gold in situ hybridization experiments. Results indicated that ' $\mathrm{Ca}$. Liberibacter solanacearum'

(CLso)-specific DNA probes annealed to a bacterium that formed extensive, monocultural biofilms on gut, salivary gland, and oral region tissues, confirming that it is one morphotype of potentially others, that is rod-shaped, approximately $2.5 \mu \mathrm{m}$ in diameter and of variable length, and has a rough, granular cytosol. In addition, CLso, prepared from shredded midguts, and negatively stained for TEM, possessed pili- and flagella-like surface appendages. Genes implicating coding capacity for both types of surface structures are encoded in the CLso genome sequence. Neither type was seen for CLso associated with biofilms within or on digestive organs, suggesting that their production is stimulated only in certain environments, putatively, in the gut during adhesion leading to multiplication, and in hemolymph to afford systemic invasion.
\end{abstract}

'Candidatus Liberibacter solanacearum' (CLso) (Rhizobiaceae; Alphaproteobacteria) first became of concern as a pathogen of potato and tomato crops in Mexico, Honduras, and the Southwestern United States when unprecedented outbreaks of zebra chip of potato and vein greening of tomato diseases emerged during the 1990s, and then spread rapidly throughout Central America, Mexico, and the Western United States (Abad et al. 2009; Brown et al. 2010; Crosslin et al. 2010; Rehman et al. 2010; Secor et al. 2009). Hansen et al. (2008) first reported the association of ' $\mathrm{Ca}$. Liberibacter' with the potato psyllid (PoP) and with diseased potato and tomato plants, based on polymerase chain reaction (PCR) amplification of the 16S rRNA gene, and proposed the name ' $\mathrm{Ca}$. Liberibacter psyllaurous' for the suspect plant bacterial pathogen. Identification of the bacterium as a member of the genus ' $\mathrm{Ca}$. Liberibacter' was based on the high shared nucleotide (nt) identities at 94 to $97 \%$, between the 16S rRNA gene of ' $\mathrm{Ca}$. L. americanus', asiaticus (CLas), and africanus (Crosslin et al. 2010), the three recognized causal agents of the citrus greening disease, also known as Huanglongbing (HLB). Concurrent with the report by Hansen et al. (2008) was the discovery of symptomatic tomato plants in New Zealand infected with an isolate of ' $\mathrm{Ca}$. Liberibacter' that shared 99 to $100 \%$ nt identity with ' $C a$. L. psyllaurous' (Liefting et al. 2008). Results of phylogenetic analysis of the 16S rRNA and $r p 1 J$ genes, and a portion of the beta operon, led to the renaming of the organism to conform to the International Code of Nomenclature of Bacteria as ' $\mathrm{Ca}$. L. solanacearum', which considers the primary hosts of the bacterium to be solanaceous plant species instead of the psyllid vector (Liefting et al. 2009). Recently, CLso (or a close relative) has

Corresponding author: J. K. Brown; E-mail address: jbrown@ag.arizona.edu

*The $\boldsymbol{e}$-Xtra logo stands for "electronic extra" and indicates that five supplementary figures are published online.

http://dx.doi.org/10.1094/PHYTO-04-15-0088-R

(C) 2016 The American Phytopathological Society been found infecting carrot and celery (Apiaceae) in Algeria, Finland, Morocco, and Spain (Munyaneza et al. 2010; Nelson et al. 2013; Tahzima et al. 2014; Teresani et al. 2014), indicating the pathogen has a broader than expected host range.

The bacterium associated with citrus greening disease was the first species of Liberibacter to be associated with a plant disease (HLB), and although many different approaches have been implemented to demonstrate causality, this has not been accomplished given its fastidious (unculturable) nature (reviewed by Gottwald et al. 2007). The history of HLB has influenced perspectives surrounding other psyllid-Liberibacter associated diseases recognized primarily during the last decade. In the mid-1960s, the causal agent of HLB was thought to be a virus based on the foliar chlorosis and decline symptom phenotypes (Fraser et al. 1966). Later, it was recognized as a prokaryote, but was initially misidentified as a mycoplasma (Laflèche and Bové 1970).

Attempts to culture the causal agent (Garnett 1985; Ghosh et al. 1971, 1975; Sechler et al. 2009; Sodhi and Dhillion 1973; Sodhi et al. 1975) led to the realization that Koch's postulates, in the classical sense, could not be met owing to the fastidious, obligate, and therefore unculturable nature of the bacterium. In this light, a number of approaches were applied to provide direct and indirect evidence for causality, and to facilitate its characterization in the plant and psyllid, now provisionally, ' $\mathrm{Ca}$. Liberibacter' (Ariovich and Garnett 1989; Chen et al. 1971; Davis et al. 2008; Hilf et al. 2013; Parker et al. 2014; Sechler et al. 2009).

Using transmission electron microscopy (TEM), Liberibacterlike bacteria were found in the salivary glands (SGs) of the South African psyllid Trioza erytreae (Del Guercio) (Moll and Martin 1973) and the Asian citrus psyllid (ACP) (Chen et al. 1973), respectively. Their observations were consistent with previously reported diagnostic features. Using scanning electron microscopy (SEM), M. Davis first demonstrated that the dissected midgut, e.g., the filter chamber and ventriculus, of ACP was covered by bacterial biofilms thought to represent CLas (Wang and Trivedi 
2013). Various lines of evidence, e.g., transmission characteristics, gut-associated biofilm, and others (Hansen et al. 2008; Liefting et al. 2009; Wang and Trivedi 2013), suggested that CLso could have a circulative and/or propagative relationship with the PoP vector. This led Ammar et al. (2011a,b) to investigate, using molecular detection (e.g., PCR amplification), whether CLas was similar to other fastidious plant-pathogenic bacteria, such as mycoplasmas and spiroplasmas, by multiplying and circulating in their hemipteran vectors (Alivizatos 1982; see references in Ammar et al. 2011a,b; Sodhi et al. 1975). The study showed that CLas was detectable by PCR in the alimentary canal (gut) and salivary glands, and that CLas titer varied by organ or tissue type, as has been demonstrated for both nonpropagative and propagative bacterial plant pathogens transmitted by hemipteran vectors. Such evidence was suggestive of a circulative nature but did not confirm or refute CLas multiplication in the psyllid host. Subsequently, Ammar et al. (2011b) used fluorescence in situ hybridization (FISH) to provide indirect evidence of CLas presence/detection in the SGs and midgut, and in the Malpighian tubules, hemolymph, ovaries, and in muscle and fat tissues. Based on several better-understood hemipteran-fastidious bacterial study systems, the latter results suggested that CLas was propagative and circulative in the psyllid vector. Likewise, for CLso-infected potato and tomato plants, the bacterium was observed in the phloem by TEM (without labeling) (Liefting et al. 2009, Secor et al. 2009), and indirectly, in PoP organs using FISH to localize the bacterium in psyllid organs in relation to transmission characteristics (Cooper et al. 2014, Sengoda et al. 2014).

Other bacteria ranging from free-living to primary or secondary endosymbionts, as well as several Wolbachia species, have been associated with HLB-affected citrus, and potato and tomato affected by zebra chip and vein-greening, respectively, and carrot plants affected by carrot yellows (see references in Haapalainen 2014; Saha et al. 2012). As such none have been ruled out as possible affiliates with Liberibacter that could also be involved in the disease syndromes (Nachappa et al. 2011, 2012; Saha et al. 2012).

Even so, without unequivocal proof of causality, ' $\mathrm{Ca}$. Liberibacter' species have become widely accepted as the causal agents of their respective diseases, based on their consistent association with disease-specific symptoms in the plant host and psyllid-mediated transmission.

Here, TEM colloidal gold in situ hybridization and FISH were implemented to establish visually definitive, morphotypic features of in situ CLso that differentiate it from the other bacteria that might be associated with the internal organs of PoP. Also, the observation of two types of CLso surface appendages, which are likely essential for adhesion-colonization in the gut (and perhaps elsewhere) and for motility in the hemolymph to afford systemic invasion and circulation, provide two new, direct lines of support for circulative-propagative, psyllid-mediated transmission of CLso.

\section{MATERIALS AND METHODS}

Colonies. Anatomical and transmission studies were carried out using CLso-infected $\left(\mathrm{CLso}^{\oplus}\right)$ and CLso-free $\left(\mathrm{CLso}^{\ominus}\right)$ adult PoP. A potato psyllid colony (central haplotype [Swisher et al. 2012]) was established from CLso-infected psyllids obtained from greenhousegrown tomato plants in Snowflake, AZ during 2004. A second colony was established using CLso-free, or uninfected potato psyllids (central haplotype [Swisher et al. 2012]) collected from potato fields in Texas during 2006, courtesy of J. Munyaneza (USDA-ARS, Yakima, WA). The psyllid colonies were reared on tomato plants grown in ventilated insect cages (Bug Dorms, BioQuip Products, Rancho Dominguez, CA) in separate growth rooms maintained at 22 to $24^{\circ} \mathrm{C}$ under a $12: 12 \mathrm{~h}$ light cycle, at the University of Arizona, Tucson. Twenty psyllids were collected randomly from colonies and tested monthly for presence or absence of CLso, respectively, using PCR amplification and CLso-specific 16S rRNA primers OA2 (Liefting et al. 2008) and O12C (Jagoueix et al. 1996) that yield a 1,160-bp amplicon. Both the $\mathrm{CLso}^{\oplus}$ and $\mathrm{CLso}^{\ominus}$ psyllid colonies were haplotyped as the "central-type" using the cytochrome oxidase I (COI) gene-specific primers and PCR amplification followed by DNA sequencing of the 500-bp COI amplicon (Swisher et al. 2012).

TEM colloidal gold in situ hybridization. Genomic DNA, prepared from $\mathrm{CLso}^{\oplus} \mathrm{PoP}$ adults, was used to amplify three CLso genes; 16S ribosomal RNA (CKC_r06093), outer membrane protein (OMP) (CKC_01195), and an ABC transporter (CKC_00595). BLAST analyses of the OMP (604 bp), 16S rRNA $(1,168 \mathrm{bp})$, and $\mathrm{ABC}$ transporter $(444 \mathrm{bp})$ probe nucleotide sequences were $100 \%$ identical to the targeted CLso-specific sequence. The 16S RNA probe sequence shares $\sim 97 \%$ nt identity with CLas, but CLas does not infect potato/tomato and is not transmitted by PoP. And none of the known primary or secondary endosymbionts of PoP share high sequence identity with the selected CLso genes/sequence targets.

Digoxigenin (DIG)-labeled DNA probes were prepared using the PCR DIG probe synthesis kit (Roche, Indianapolis, IN). The labeling reaction consisted of $2 \mu \mathrm{l}$ of CLso ${ }^{\oplus} \mathrm{PoP}$ gDNA, $5 \mu \mathrm{l}$ of PCR buffer with $\mathrm{MgCl}_{2}, 5 \mu \mathrm{l}$ of the DIG-labeled probe, $5 \mu \mathrm{l}$ of each primer $(20 \mu \mathrm{M}), 0.75 \mu \mathrm{l}$ of enzyme mix, and $27.25 \mu \mathrm{l}$ of nucleasefree water. The PCR cycling conditions were $95^{\circ} \mathrm{C}$ for $2 \mathrm{~min}$ and then 30 cycles of $95^{\circ} \mathrm{C}$ for $30 \mathrm{~s}, 58^{\circ} \mathrm{C}$ for $30 \mathrm{~s}, 72^{\circ} \mathrm{C}$ for $60 \mathrm{~s}$, and final elongation at $72^{\circ} \mathrm{C}$ for $10 \mathrm{~min}$. The PCR products from unlabeled PCR reactions (e.g., minus the DIG probe synthesis mix) were cloned into the pGEM-T pGEM-T Easy Vector (Promega, Madison, WI) and at least three independent plasmid clones were used for sequence verification. Verification of labeled probes was performed by both gel electrophoresis and colorimetric detection (NBT/BCIP, Roche). The three labeled probes were mixed, quantified with a Nanodrop ND-1000 (Nanodrop Technologies, Wilmington, DE), denatured for $10 \mathrm{~min}$ at $95^{\circ} \mathrm{C}$, cooled in ice, and used in hybridization reactions ( $1 \mu \mathrm{l}$ per $100 \mu \mathrm{l}$ of hybridization buffer). The concentration of the probe cocktail was estimated to be $450 \mathrm{ng} / \mu \mathrm{l}$.

Six to eight $\mathrm{CLso}^{\oplus}$ and $\mathrm{CLso}^{\ominus}$ adult PoP per replicate were randomly collected, glued, venter up, to a thumbtack embedded in a paraffin-filled, plastic microwatchglass (Orach Machine Shop Service, Tucson, AZ), submerged in water, and cleared of any adhering bubbles with ducosate sodium (Aerosol OT, a wetting agent [Sigma-Aldrich, St. Louis, MO]). After rinsing and refilling with $4 \%$ formaldehyde and $0.5 \%$ glutaraldehyde in $0.01 \mathrm{M} \mathrm{Na}^{+}-\mathrm{K}^{+}$phosphate buffered saline (PBS) (Sambrook et al. 1989), $\mathrm{pH} 7.75$, the tip of the abdomen, legs, hind coxae, stylet bundle, and anterior of the head were removed with microdissecting scissors (Electron Microscopy Sciences, Hatfield, PA). After $24 \mathrm{~h}$, PoP abdomens were collected with a transverse cut across the hind coxal cavities. The heads and SGs were obtained by trimming away the metathorax. Specimens were transferred to a borosilicate test tube and rinsed with PBS two times for $15 \mathrm{~min}$. The PBS was replaced with Carnoy's fixative (6:3:1, ethanol/chloroform/acetic acid) (Ghanim et al. 2009) for $5 \mathrm{~min}$ and rinsed with $100 \%$ ethanol.

Infiltration of specimens was carried out by immersion in $25 \%$ LR White (EMS) for $6 \mathrm{~h}$. Specimens were then transferred to separate test tubes for continued infiltration (75\% overnight, $100 \%$ $6 \mathrm{~h})$ to avoid autopolymerization. Embedment vessels were prepared by polymerizing, under nitrogen, $250 \mu \mathrm{l}$ of LR White in 1.5 -ml microfuge tubes overnight at $52^{\circ} \mathrm{C}$. After rinsing and filling with LR White, one specimen each was added to the vessel for final polymerization.

Sections were collected and dried on uncoated, 200 mesh gold grids. Grids were kept fully immersed in a Pyramid-tip embedding mold (Ted Pella, Inc. Redding, CA) during each step of the labeling 
process and not allowed to dry during each well-to-well transfer to prevent nonspecific background deposition.

Grids were prehybridized in hybridization buffer (HB) containing $20 \mathrm{mM}$ Tris- $\mathrm{HCl}, \mathrm{pH} 8.0,0.5 \mathrm{M} \mathrm{NaCl}, 0.01 \%$ (wt/vol) sodium dodecyl sulfate, and $30 \%$ (vol/vol) formamide at $42^{\circ} \mathrm{C}$ for $30 \mathrm{~min}$, followed by hybridization overnight in a probe cocktail diluted 1:100. Grids were washed with $\mathrm{HB}$ for $15 \mathrm{~min}$, and then rinsed with Buffer I (20 mM Tris- $\mathrm{HCl}, \mathrm{pH} 8.0,0.05 \mathrm{M}$ $\mathrm{NaCl}$ ) two times for $15 \mathrm{~min}$, followed by sodium chloride/sodium citrate $(20 \times \mathrm{SSC}=3.0 \mathrm{M} \mathrm{NaCl}, 0.375 \mathrm{M}$ sodium citrate $)$ stringency rinses $(2 \times \mathrm{SSC}$ for $15 \mathrm{~min}, 1 \times \mathrm{SSC}$ for $5 \mathrm{~min}$, and $0.5 \times \mathrm{SSC}$ for $5 \mathrm{~min})$. After the challenge, grids were rinsed with Buffer I for $10 \mathrm{~min}$ and then blocked in Buffer II ( $0.5 \mathrm{~g}$ of blocking powder [Roche] and $0.1 \mathrm{mg}$ of bovine serum albumin in $100 \mathrm{ml}$ of Buffer I) for $1 \mathrm{~h}$. Samples were incubated for $1 \mathrm{~h}$ at $24^{\circ} \mathrm{C}$ with $10 \mathrm{~nm}$ sheep anti-DIG conjugated colloidal gold (EMS) at 1:1,000 in Buffer II that had been centrifuged at 5,000 RPM for 5 min before use. Grids were rinsed in Buffer I, fixed in $2.5 \%$ glutaraldehyde in Buffer $\mathrm{I}$, rinsed in $\mathrm{dH}_{2} \mathrm{O}$, and viewed under TEM without poststaining.

The condenser aperture was adjusted to over-brightness as needed to validate antibody-conjugated gold particles by their opacity and shape. Both sides of one grid were checked to see that label could be viewed in the same operational focal plane width at the optimum working magnification of 19,500×. For midguts, formal replicates consisted of sections from $\mathrm{CLso}^{\oplus}$ and $\mathrm{CLso}^{\ominus}$ PoP $\left(n=3\right.$, 3; e.g., one rep each from three different $\mathrm{CLso}^{\oplus}$ abdomens and same for $\mathrm{CLso}^{\ominus}$ abdomens) in the following arrays. Infected specimens [+probe, + gold] were accompanied by three negative controls: [-probe, +gold], [+probe, -gold], and [-probe, -gold]. Uninfected specimens were used in four negative controls: [+probe, +gold], [-probe, +gold], [+probe, -gold], and [-probe, -gold].

For SGs and the tentorium, one formal rep each $(n=1,1)$ was performed. The tentorium is a box-shaped endoskeletal structure of the oral region that supports feeding and salivation musculature.

FISH. An oligonucleotide probe cocktail was used to detect the CLso OMP and the $16 \mathrm{~S}$ ribosomal RNA (rRNA) genes. The following fluorochrome-labeled oligonucleotides were synthesized and used in FISH experiments with the PoP-CLso study system: LibOMP-5'-CAGTACCATATACTACCACAG-3' and Lib16S rRNA-5'-TACCATCTCTGATATCGTCCT-3', respectively. BLAST analysis of these short sequences were each $100 \%$ identical to the respective CLso-specific sequence target, CKC_00240 (OMP) and CKC_r06093 (16S rRNA). The 16S rRNA-specific probe was directed to the same gene and specific region targeted as the CLas-specific FISH probe utilized by Ammar et al. (2011a), and with which the CLso probe shares $100 \%$ nt identity. High specificity of both probes designed for and used in PoP experiments is expected because CLso, but not CLas, infects potato/tomato and is transmitted exclusively by PoP. Also, none of the known primary or secondary endosymbionts of PoP share high sequence identity with the selected CLso genes/sequence targets. Cyanine-5 (Cy5), or indodicarbocyanine, a fluorochrome with an absorption and emission at 650 and $670 \mathrm{~nm}$, respectively, was conjugated to the $5^{\prime}$-end of each of the probes (Integrated DNA Technologies, Inc., San Diego, CA).

FISH was carried out on poly L-lysine coated slides (Newcomer Supply, Middleton, WI) for three replicates per treatment that each contained three to five midguts per slide under coverslips (22 $\mathrm{mm}^{2}$, No. 1.5, Fisher Scientific, Waltham, MA). The negative controls were $\mathrm{CLso}^{\oplus}$ adults with no probe and $\mathrm{CLso}^{\ominus}$ adults with and without probe.

Midguts were dissected from adults into D10 feeding solution containing $1 \%$ fetal bovine serum, $0.3 \mathrm{M}$ sucrose, $0.01 \mathrm{M}$ fructose, $0.02 \mathrm{M} \mathrm{K}_{2} \mathrm{HPO}_{4}$, and $0.003 \mathrm{M} \mathrm{MgCl}_{2}$, pH 7.5 (Alivizatos 1982), spread out on slides, and briefly rinsed with TBS (20 mM Tris-
$\mathrm{HCl}, \mathrm{pH}$ 8.0, 0.5 M NaCl). After superficial drying, one drop of Carnoy's was placed on each specimen for a 5 min fixation. Midguts were then rinsed three times in HB, photographed in bright-field to permit comparison with the corresponding darkfield FISH micrographs, and then hybridized overnight with $20 \mathrm{pmol}$ fluorescent probe cocktail $/ \mathrm{ml}$, held in an Immuno Stain Moisture Chamber (Evergreen Scientific, Los Angeles, CA) at $42^{\circ} \mathrm{C}$. After hybridization, samples were washed briefly in $\mathrm{HB}$, counterstained with DAPI nucleic acid stain $(100 \mathrm{ng} / \mathrm{ml})$ (Life Technologies, Grand Island, NY), washed in HB three times for $1 \mathrm{~min}$, and mounted in $50 \%$ glycerol-TBS under a coverslip. Slides were viewed and photographed with a Nikon Diaphot 300 inverted compound microscope (Mikron Instruments, Vista, CA), fitted with $\mathrm{Cy}-5$ and DAPI filters, respectively. After photographing the specimen to record the location of the fluorescent signal, some midguts $(n=9)$ were lifted off with a single-edge blade, dehydrated, critical point dried, and viewed by SEM (data not shown). FISH was carried out for three replicates per treatment, that each contained three to five midguts per slide.

Imaging of surface appendages. $\mathrm{CLso}^{\oplus}$ and $\mathrm{CLso}^{\ominus}$ adults $(n=$ $2,2)$ were vortexed in $5 \%$ bleach for $10 \mathrm{~s}$, and midguts were extirpated in diethyl pyrocarbonate (DEPC)-treated $\mathrm{H}_{2} \mathrm{O}$. One each was transferred to the rim of a pioloform-coated grid holding $20 \mu \mathrm{l}$ of DEPC $\mathrm{H}_{2} \mathrm{O}$. Five minutes after shredding with insect pins, tissue fragments were removed, and the water was allowed to evaporate to a thin film before the addition of $2.5 \mu \mathrm{m} 4 \%$ glutaraldehyde. Specimens were fixed for $10 \mathrm{~min}$ as the media was allowed to evaporate down to a thin film. One drop of $2 \%$ uranyl acetate was added and allowed to stand for 2 min, followed by blotting with filter paper, and air drying.

RT-PCR amplification of predicted flagellum and pilus transcripts. Transcripts (predicted from the CLso genome sequence) (Lin et al. 2011) corresponding to the CLso flagellar motor A and pilus assembly genes were selected for RT-PCR amplification to determine if pilus- or flagellum-like genes were expressed in PoP adults from colonies of $\mathrm{CLso}^{\oplus} \mathrm{PoP}$, shown (above) to harbor massive CLso biofilms and freely associated CLso cells.

The flagellar motor A gene and the pilus assembly transcripts predicted from the annotated, complete CLso genome sequence (Lin et al. 2011) were identified as the GenBank gene IDs 10033450 (813 bp) and 10033490 (804 bp), respectively. The homologous flagellar motor A gene and pilus assembly protein CpaB transcripts, BcWN_62632 (109 bp) and BCWN_45414 (346 bp), were also predicted in a PoP transcriptome library (http://www.sohomoptera.org/ACPPoP). Although the goal was to construct a psyllid library, some CLso transcripts were clearly present among the annotated sequences. They were interpreted to represent Liberibacter contaminants, or transcripts that coisolated with PoP host transcripts during RNA isolation and/or cDNA synthesis, presumably because of their high abundance (Fisher et al. 2014). Also, expression profiles of CLas genes with predicted annotations as components of a flagella assembly have been documented in the psyllid and plant hosts of CLas (Yan et al. 2013).

Primers designed to amplify the CLso transcripts using RT-PCR are as follows: MotA-F-5'-CGGTAAAACTTTGCGTCCAT-3' and MotA-R-5'-GCCACGAAATTGAAACCCTA-3' to target the flagellar motor A transcript fragment (380 bp, expected size), and Pil45414-F-5' -AATGGTTCGTTTGATTGGTG-3' and Pil45414R-5'-TCATCTTGACATTTCCTCTCC-3' to target the pilus assembly transcript fragment (340 bp, expected size). Total RNA was extracted from samples using the GeneJET RNA purification kit according to manufacturer protocol (Fermenta Thermo Fisher Scientific, Inc., Waltham, MA). Briefly, $10 \mathrm{PoP}$ adults were ground in liquid nitrogen and resuspended in lysis buffer supplemented with $\beta$-mercaptoethanol and proteinase K. After centrifugation, the lysate was mixed with ethanol and applied to the GeneJET 
RNA purification spin column. RNA was eluted in $50 \mu \mathrm{l}$ of nuclease-free water. The RNA was treated with DNase (Ambion, Austin, TX). First-strand cDNA was synthesized using the Enhanced Avian HS RT-PCR kit (Sigma) with $0.25 \mu \mathrm{g}$ of RNA as the reverse primer, MotA-R or Pilus45414-R, respectively.

The RT-PCR assays were performed in a $25-\mu \mathrm{l}$ volume containing $1 \mu \mathrm{l}$ of cDNA reaction mixture, $5 \mu \mathrm{l}$ of $10 \times$ Accu Taq buffer, $1 \mu$ l of DNTP mix, $1 \mu$ l of specific primer pair (MotA-F/ MotA-R or Pilu45414-F/Pilu45414-R), $16.5 \mu$ l of distilled water, and $0.5 \mu \mathrm{l}$ of JumpStart Accu Taq LA DNA polymerase. The PCR and RT-PCR cycling conditions were $94^{\circ} \mathrm{C}$ for $2 \mathrm{~min}$, and then 35 cycles of $94^{\circ} \mathrm{C}$ for $15 \mathrm{~s}, 53^{\circ} \mathrm{C}$ for $30 \mathrm{~s}, 72^{\circ} \mathrm{C}$ for $1 \mathrm{~min}$, and final elongation at $72^{\circ} \mathrm{C}$ for $5 \mathrm{~min}$, after which the reactions were held at $4^{\circ} \mathrm{C}$.

PCR products were electrophoresed on $1 \%$ agarose gels in TAE buffer, $\mathrm{pH}$ 8.0, and visualized with GelRed (Biotium) staining. The amplicon was ligated into the pGem-T Easy plasmid vector (Promega) following the manufacturer's protocol. Clones bearing
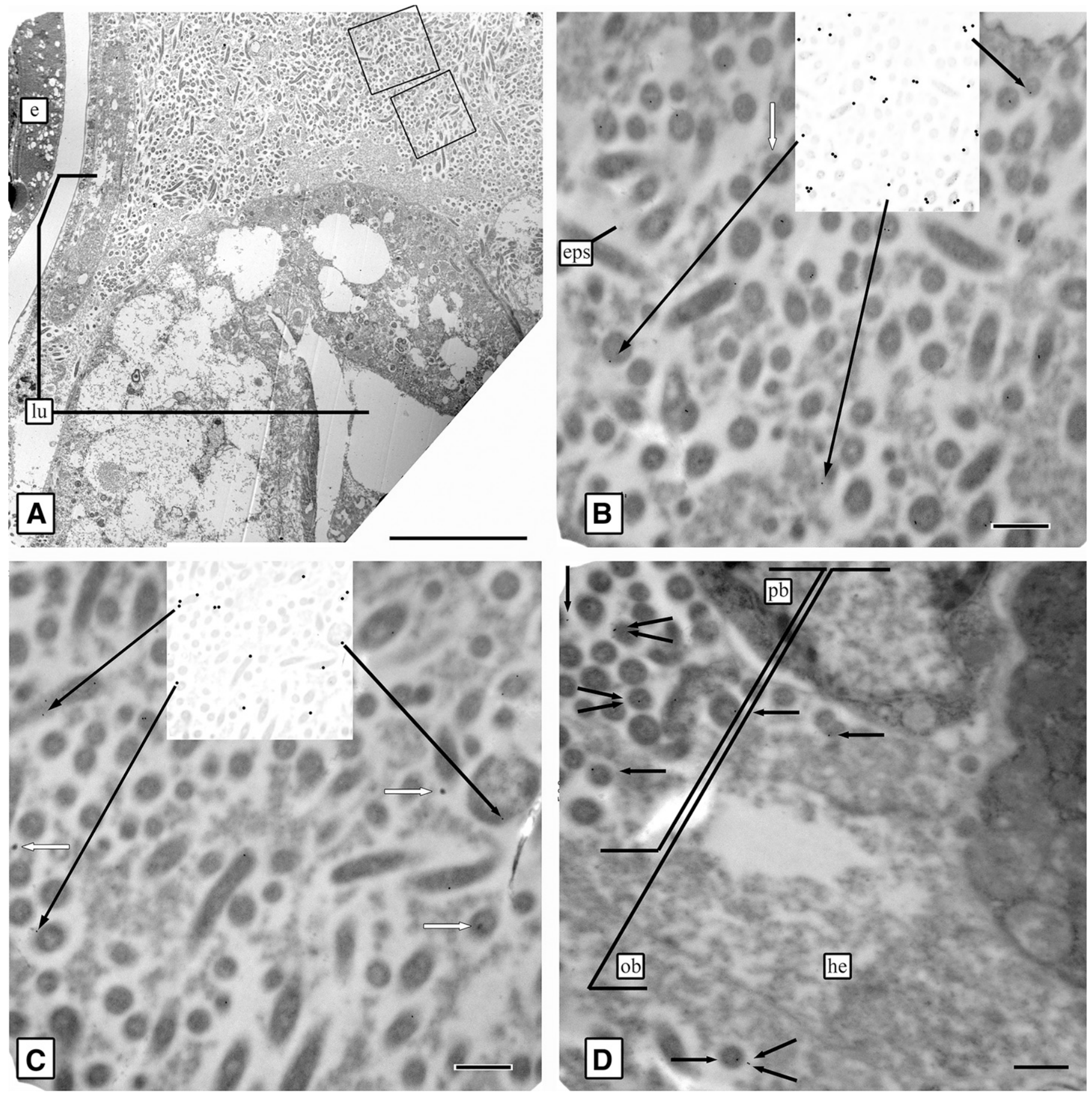

Fig. 1. Midguts. CLso-infected. Rep 1, [+probe, +gold]. Each black arrow points to one gold particle. White arrows, foreign particulate. Negative controls, Figure 2. A, Low magnification of 2,650× for panoramic view of the massive 'Candidatus Liberibacter solanacearum' biofilm. Upper inset, location of B. Lower inset, location of C. Line $=10 \mu \mathrm{m}$. B, Operational magnification of 19,500× for viewing $10 \mathrm{~nm}$ antibody-conjugated gold label. Inset, reader assist maps all gold particles in the micrograph. All label is located on a bacterium, and on or close to its peripheral margin. Line $=0.5 \mu \mathrm{m}$. C, Lower inset in A. Many labels are close to the periphery of bacteria, others are more mesal. Line $=0.5 \mu \mathrm{m}$. D, Different section, showing nontarget tissue. Line $=0.5 \mu \mathrm{m}$. lu, midgut lumina. e, egg. eps, extracellular polymeric substance. pb, periphery of biofilm. ob, outside the biofilm. No gold, conjugated or free, is present. he, hemolymph. 


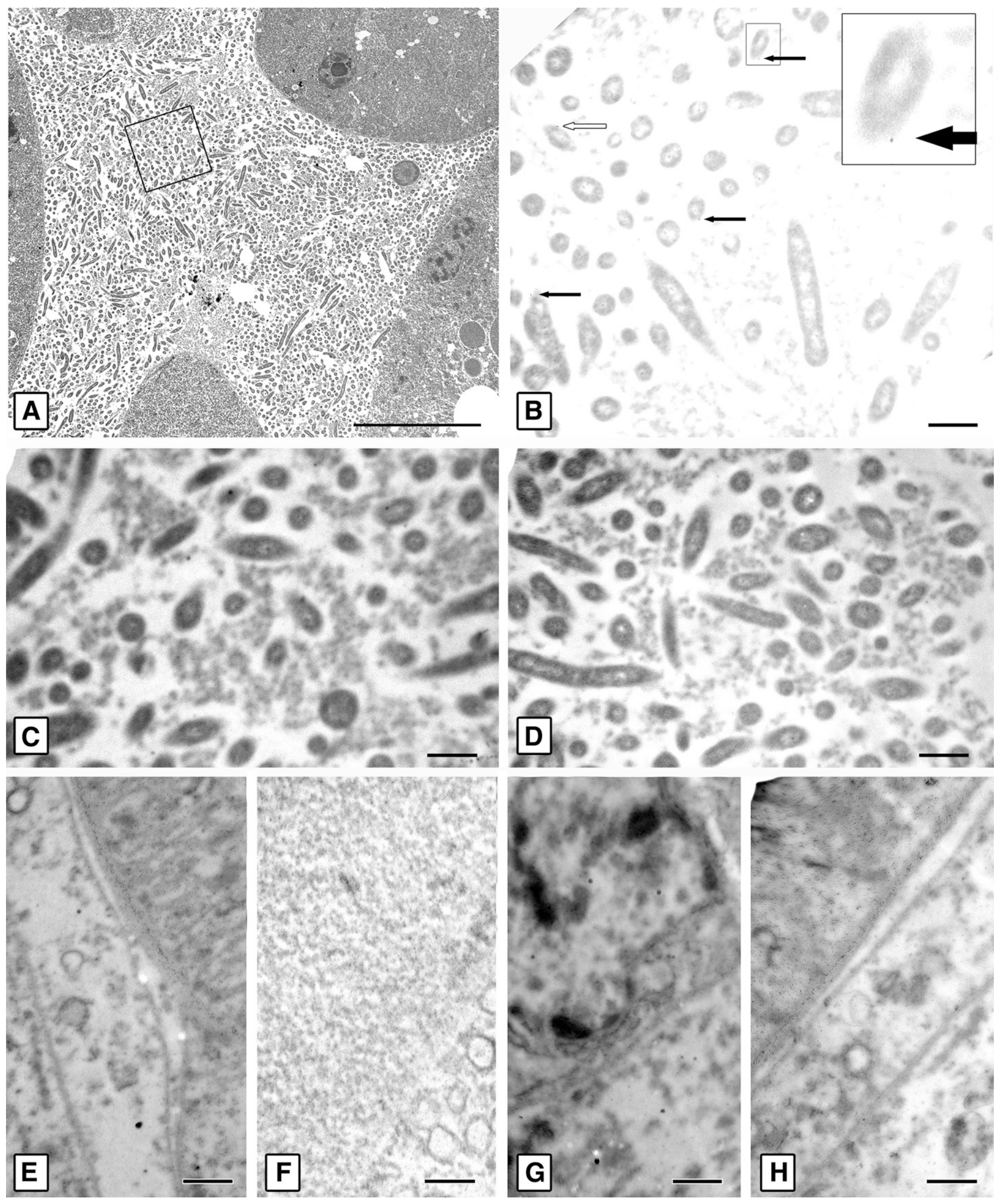

Fig. 2. Midguts. Negative controls for rep 1, Figure 1. A, CLso-infected [-probe, +gold]. Zoom-out with inset for B. Line $=10 \mu \mathrm{m}$. B, C, and D, CLso-infected. Lines $=0.5 \mu \mathrm{m}$. B, Inset from A. Over-brightened to allow quick and unambiguous detection of gold, whether conjugated or free. Black arrows, nonspecific labeling on three bacteria. These were the only gold particles on the section. Inset, nonspecific labeling on periphery of bacteria. White arrow, foreign particulate. $\mathbf{C}$ to $\mathbf{H}$, No gold, conjugated or free, is present. C, [+probe, -gold]. D, [-probe, -gold]. E to F, CLso-infected. Lines $=0.5 \mu \mathrm{m}$. E, [+probe, +gold]. F, [-probe, +gold]. G, [+probe, -gold]. H, [-probe, -gold]. 
inserts of the expected size were verified by colony PCR using M13 forward and reverse primers followed by DNA sequencing (Genetics Core Facility, University of Arizona, Tucson).

\section{RESULTS}

Electron microscopy. All experimental replicates confirmed that massive biofilms of rod-shaped bacteria were embedded in and discretely spaced from each other in an electron-transparent matrix, herein interpreted as an extracellular polymeric substance (EPS) (Figs. 1A and 2A). The EPS was observed on the outer surface of the midgut, SGs, and inside the tentorium. Thorough inspection of the biofilms revealed that they were monocultural, e.g., no other bacterial form was associated with them. Circularshaped and oval-shaped sections of the bacterium were observed separately from, and mixed together with, longitudinal sections of the rod-shaped form. Although the cytosol of all three appeared to be the same, it was not possible to determine whether circular and oval bacterial forms were present, because transverse and diagonal cross-sections of the rod-shaped form could also have those respective appearances. Therefore, only the rod-shaped form is considered to represent the predominant bacterium within the psyllid, not discounting the possibility of others.
Sparse, definitive, and consistent signal, with negligible background, was detected from these bacteria on establishing optimum stringency challenges. Discrete views of gold particles on both sides of ultrathin sections were obtained when viewing one side at the operational focal plane (Supplementary Fig. S1). "Background" refers to hemolymph (Fig. 1D), to tissue that biofilms appear adherent to, and to the EPS between bacteria (Fig. 1B). The use of uncoated grids increased the intensity of the signal to appreciable levels.

TEM colloidal gold in situ hybridization. Sparse, definitive, and consistent signal was observed with negligible nonspecific background in replicates of the abdomen, tentorium, and SGs. The most abundant positive signal was observed on the peripheral margin of CLso (Fig. 1B). With one exception, the negative controls showed no evidence of nonspecific binding (Figs. 2C to $\mathrm{H}, 3 \mathrm{C}$ to J, 4C to E, and 5A to D and Supplementary Figures). The one exception (Fig. 2B) showed the presence of three gold particles, one each on the periphery of a CLso, indicating nonspecific binding of gold in the absence of probe.

FISH (Fig. 6). FISH experiments showed fluorescence that was consistently localized to the filter chamber, whereas, the signal localized to the ventricular loop was observed in only several specimens, and in these cases, signal, both weak and strong, was
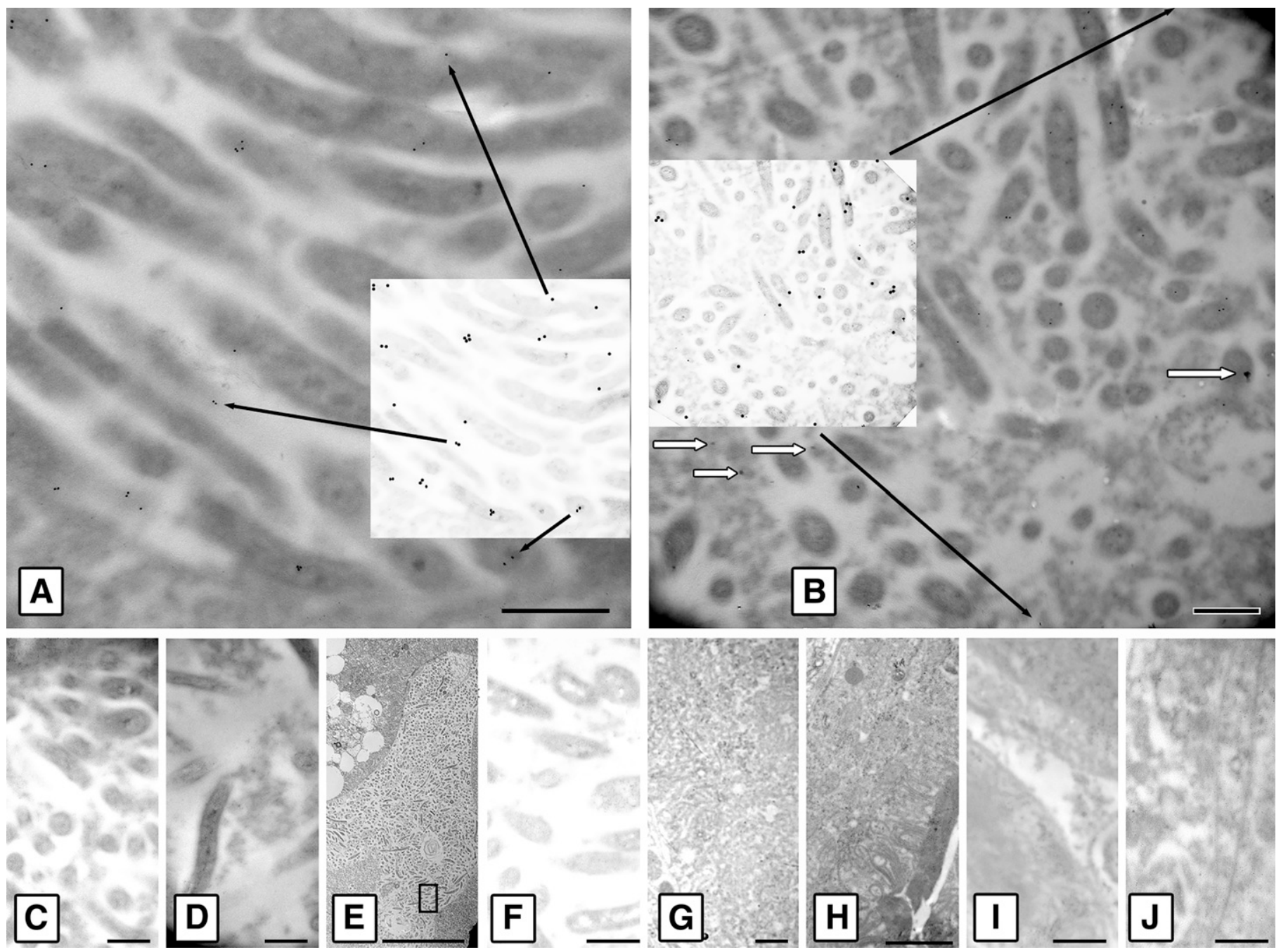

Fig. 3. Midguts. A and B, CLso-infected. Lines $=0.5 \mu \mathrm{m}$. A, Rep 2, [+probe, +gold]. B, Rep 3, [+probe, +gold]. White arrows, foreign particulate. Negative controls, Supplementary Figs. S2 and S3. C to J, Negative controls for A. No gold, conjugated or free, is present. C to F, CLso-infected. G to J, CLso-uninfected. $\mathbf{C}$, [-probe +gold]. Line $=0.5 \mu \mathrm{m}$. D, [+probe, -gold]. Line $=0.5 \mu \mathrm{m}$. E, [-probe -gold]. Zoom-out showing massive biofilm. Inset, location of F. Line $=10 \mu \mathrm{m}$. F, [-probe, - gold] . Line $=0.5 \mu \mathrm{m}$. G, [+probe, + gold]. Line $=0.5 \mu \mathrm{m}$. H, [-probe, +gold]. Zoom-out showing absence of biofilm. Line $=2 \mu \mathrm{m}$. I, [+probe, - gold] . Line $=0.5 \mu \mathrm{m}$. J, [-probe, - gold $]$. Line $=0.5 \mu \mathrm{m}$. 
confined to small areas (Fig. 6A). In Figure 6A, strong labeling in the filter chamber allowed for recognition of the helical windings of the inner ventriculus. The negative controls showed no evidence of labeling (Fig. 6B).

TEM imaging of surface appendages. Large numbers of bacteria agreeing in size, shape, and abundance, with those visualized by TEM colloidal gold, were observed in a density gradient on negatively stained grids, from numerous at the rim, where shredding was done, to more sparse toward the center (Figs. 7 and 8). The interior of these cells displayed a granular electron opacity that was far more predominant than that of plasticembedded, sectioned cells, indicating uranyl acetate uptake leading to positive staining, in addition to faint negative staining. Also, amorphous, globular, electron transparent masses, thought to represent EPS, adhered to the CLso cells (Fig. 7A).

Long, strand-like appendages, one or several per cell, were observed extending from the sides of some CLso cells, and appeared to be of two distinct types. The bundled appendages (Fig. 7) appeared to comprise tightly wound fibers reminiscent of previously studied Type IV pili (Tomich et al. 2007), each having a diameter of 0.005 to $0.008 \mu \mathrm{m}$. It was difficult to estimate the diameter of the bundles because the fibers were composed of 10 or more per group, and they were variably loosely or tightly associated. The lone appendages were ca. $0.02 \mu \mathrm{m}$ in diameter (Fig. 8). No bacteria-like forms or pilus-like or flagellum-like structures were observed on grids with the negative control. Further, in no case were
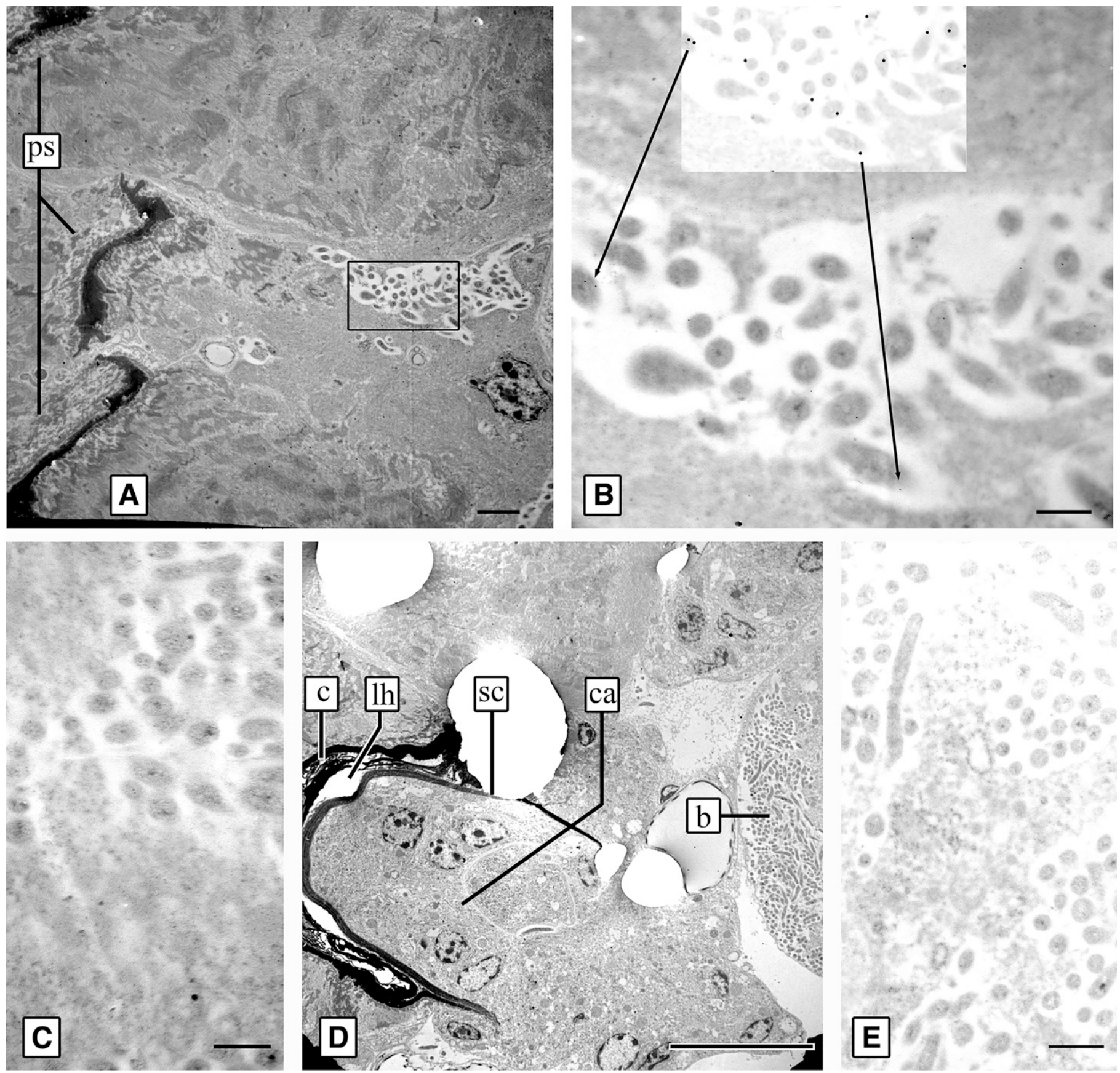

Fig. 4. Tentorium. CLso-infected. A, [+probe, +gold]. Zoom-out, inset locates B. Line $=2 \mu \mathrm{m}$. B, Close-up of A with reader-assist inset locating all antibodyconjugated gold within its bounds. Line $=0.5 \mu \mathrm{m}$. C to E, Negative controls. No gold, conjugated or free, is present. Remaining negative controls, Supplementary Fig. S4. C, [-probe, +gold]. Line $=0.5 \mu \mathrm{m} . \mathbf{D},[+$ probe, - gold] . Zoom-out showing biofilm adjacent to stylet base. Line $=10 \mu \mathrm{m} . \mathbf{E}$, [-probe, - gold] . Line $=0.5 \mu \mathrm{m}$. ps, precibarial sensillar units (Ullman and McLean 1986). c, cushion. lh, loading sleeve hollow. sc, stylet cuticle. ca, cell assemblage inside the base of the stylet. b, biofilm. 
flagella, pili, or other appendages of any kind attached to or associated with the bacterial cells observed by TEM in anatomical cross-sections of $\mathrm{CLso}^{\oplus} \mathrm{PoP}$.

The RT-PCR amplicons of the expected sizes, 380 and $340 \mathrm{bp}$, respectively, were obtained for the flagellar motor $\mathrm{A}$ and the pilus assembly putative transcripts from $\mathrm{CLso}^{\oplus}$ adult PoP, but not from CLso $\odot$ adult PoP. Cloning and DNA sequencing of the two amplicons revealed that they shared a high nucleotide identity with the respective reference sequence for each gene. The PoP flagellar motor A sequence obtained was $99 \%$ identical to the NCBI reference genome sequence (Gene ID 10033450) and shared 100\% identity with the 109-bp transcript (BcWN_62632), respectively. Likewise, the pilus assembly sequence obtained shared $99 \% \mathrm{nt}$ identity to the annotated reference transcript (BcWN_45414). The flagellar motor $A$ and pilus assembly sequences were submitted to the NCBI GenBank database and assigned the accession numbers JX629450 and JX629449, respectively.

\section{DISCUSSION}

In this study, the use of TEM colloidal gold in situ hybridization allowed for the first definitive, visual identification of CLso in the
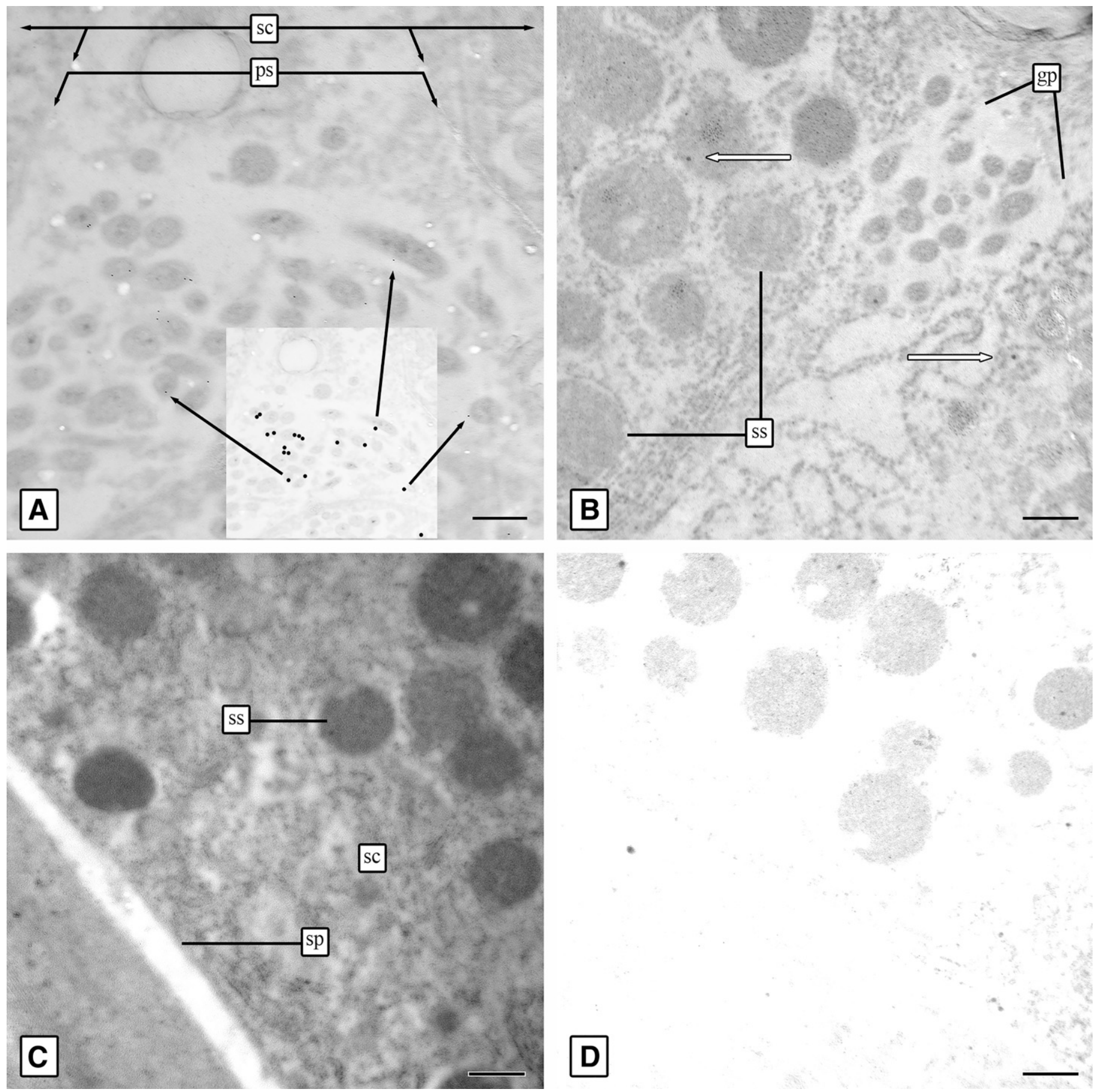

Fig. 5. Salivary glands. Lines $=0.5 \mu \mathrm{m}$. A, CLso-infected [+probe, +gold]. CLso are in gland pericellular space. $\mathbf{B}$ to $\mathbf{D}$, Negative controls. No gold, conjugated or free, is present. B, CLso-infected [-probe, +gold]. White arrows, foreign particulate. C, CLso-uninfected [+probe, +gold]. D, CLso-uninfected [-probe, +gold]. Remaining negative controls, Supplementary Fig. S5. sc, secretory cells. ps, CLso is in gland pericellular space. gp, CLso is at gland periphery. ss, secretory spherules. sp, salivary gland periphery. 
PoP host. The following character set defines the labeled CLso cells as one morphotype of potentially others, such as a putative coccoid form: elongate, rod-shaped, ca. $250 \mathrm{~nm}$ in diameter and of variable length, and with a rough, granular cytosol that characteristically and specifically agrees with those in the colloidal gold-validated TEM micrographs. Also reported here is the first visual evidence for CLso-associated pili- and flagella-like surface appendages, and the possible presence of surface polysaccharides, albeit residual and incompletely covering the bacterial cell, or putative EPS, clinging to a portion of the bacterial cell in negatively stained specimens (Figs. 7 and 8). The absence of appendages on CLso cells in anatomical sections viewed by TEM further supports the suggestion that appendages are produced only in certain environments, perhaps in those requiring motility and re-adhesion.

The bacterial morphotype localized in the PoP digestive system is, with certain exceptions (Mann et al. 2011; Shokrollah et al. 2010), consistent with the morphology of the bacterium previously identified as a ' $C a$. Liberibacter' species in high-resolution micrographs of cultures from citrus (Ariovich and Garnett 1985), of phloem in diseased citrus (Bove 2006; Chen et al. 1971; Garnier and Bové 1983; Hilf et al. 2013; Massonie et al. 1976), potato (Liefting et al. 2009; Secor et al. 2009), and carrot (Nissinen et al. 2014), and in infected citrus psylla (Trioza erytreae Del Guercio) (Moll and Martin 1973), and ACP (Chen et al. 1973).

Serial sectioning was not performed to differentiate a coccoid form from transverse sections of rod forms; therefore, TEM observations were not able to unequivocally confirm that a coccoid form of ' $\mathrm{Ca}$. Liberibacter' occurred in any of the specimens. For this same reason, the interpretations made by Ariovich and Garnett (1985) are not substantiated given their TEM methods and micrographs. Direct colloidal gold localization of CLso in the PoP host is attributed to combining conventional FISH technique with the methods of Ghanim et al. (2009) for simple, rapid, and inexpensive FISH that relies exclusively on Carnoy's fixative. Use of Carnoy's as a brief postfixative to aldehydes promotes denaturation and annealing of probe. Use of glutaraldehyde and formaldehyde facilitates sufficient retention of ultrastructure to recognize tissues and cell types. Given the negligible nonspecific labeling observed in the negative controls (Fig. 2B), the combined approaches yielded consistent, high-quality detection, anatomical localization, and identification of ' $\mathrm{Ca}$. Liberibacter' species. The methods are additionally promising for localizing transcripts of interest to in situ locations in well-preserved specimens (Binder et al. 1986; Javelle et al. 2011).

Colloidal gold-TEM and other in direct in situ hybridization methods provide more robust proof of identification and localization, compared with the FISH method employed herein. The latter has several drawbacks for pathogen detection. First, the method cannot directly ascertain whether the probes cross-hybridize with other, unknown, species that share sequence homology with the probe. Secondly, the method cannot determine whether the signal occurs in the inside or on the outside of the midgut. Lastly, there is the potential for biofilms to be washed off the external surfaces of the midgut into the aqueous hybridization and rinsing media, causing loss of signal.

The method confirmed the presence of CLso inside the filter chamber (Fig. 6A) because, in that specimen, the signal was located in such a way as to allow the inner ventriculus to be identified by its helical configuration. However, as above, this micrograph does not indicate whether the bacteria are in the lumen of, or on the outside surface of, the inner ventriculus, or in the periventricular space between it and the sheath.

Figures 1A, 2A, and numerous other TEM micrographs (J. Cicero, unpublished data) show that the midgut of $\mathrm{CLso}^{\oplus} \mathrm{PoP}$ can be exteriorly surrounded by massive biofilms. Since the biofilms are indicated to be composed exclusively of CLso, we conclude that the technique of transferring and shredding midguts at TEM grid rims promoted dissociation and diffusion of the bacteria into viewable positions for negative staining (Figs. 7 and 8), and that these bacteria are in fact CLso. Two types of surface appendages, pili and flagella, were observed.

The Type IV pilus is the most common and the best-studied pilus type among bacterial pathogens. It is commonly known to contribute to virulence by mediating cell-to-cell interactions, including adherence to cells of the bacterial host (Aizawa 2002; Saad et al. 2005, Zatakia et al. 2014). Type IV pili can form tightly
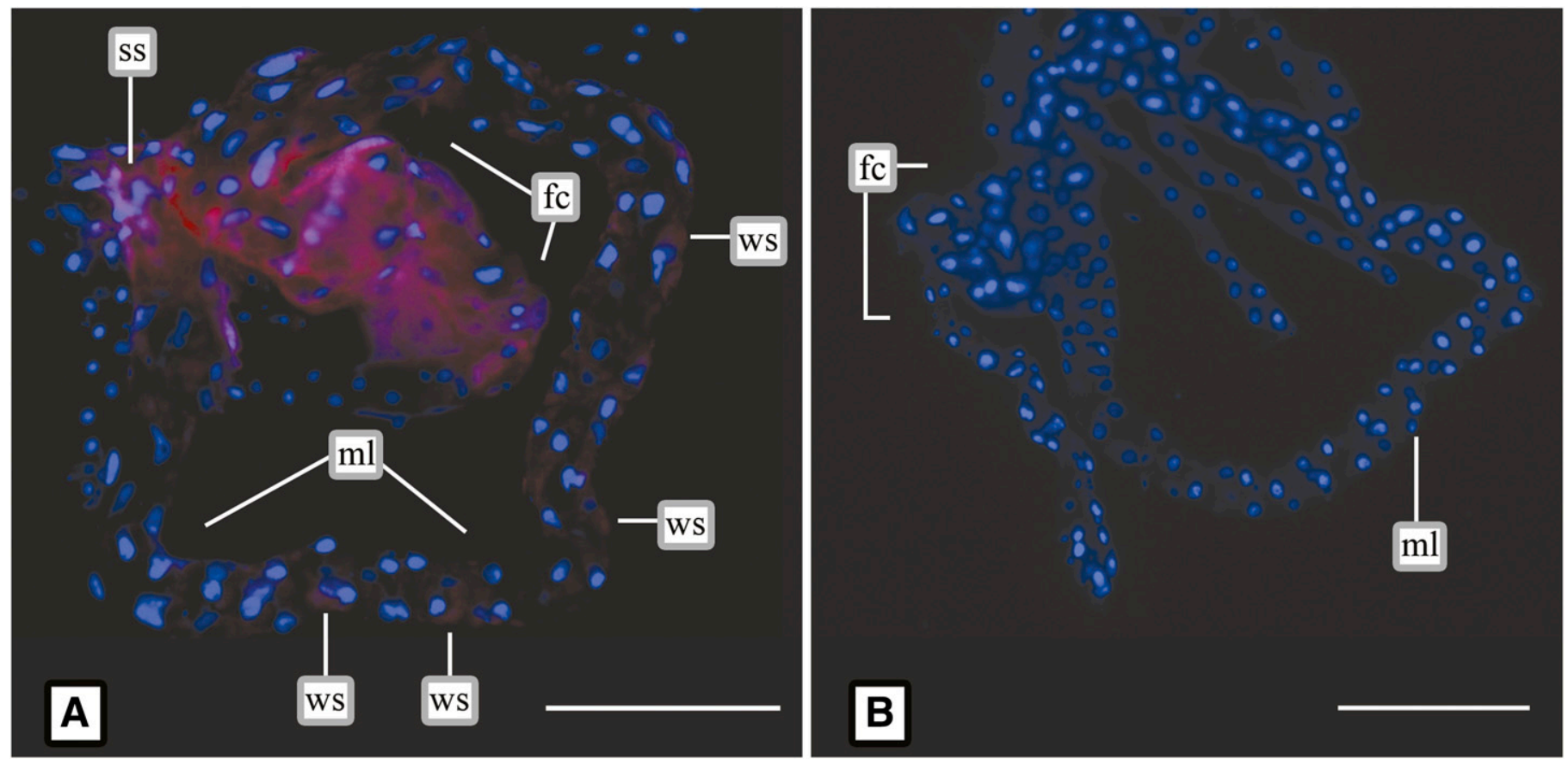

Fig. 6. Fluorescence in situ hybridization detection of CLso in midguts. Blue shows DAPI and red shows Cy5. Lines $=200 \mu \mathrm{m}$. A, CLso-infected. B, CLsouninfected. Negative control. fc, filter chamber. The inner ventricular helix is recognizable in A. ml, midgut loop. ss, strong CLso detection signal. ws, weak CLso detection signal. 
wound bundles of fibers that are often 5 to $8 \mathrm{~nm}$ in diameter, and they can extend to several micrometers in length from the bacterial surface (Tomich et al. 2007), as was observed here (Fig. 7). The putative CLso Type IV pilus gene cluster is organized in an operon containing nine genes that have homology to the tad/flp Type IV pili family (Kanehisa et al. 2002). The tad (tight adherence) genes, which are essential for biofilm formation, colonization, and pathogenesis in many genera, are confined in a 14-gene locus (Tomich et al. 2007). At least 12, but most likely 13 of these are usually required for all adherence-related phenotypes, including Flp-pilus production and biofilm formation in Aggregatibacter actinomycetemcomitans (Tomich et al. 2007). Tightly wound bundles of fibers highly reminiscent of Type IV pili were observed attached to and emanating from the surface of CLso cells (Fig. 7). To corroborate this observation genetically, the expression of a pilus assembly CpaB-like messenger RNA (mRNA) (Gene ID 10033490; locus tag ckc_00710) was analyzed using RT-PCR amplification of mRNA from total RNA extracts of CLso ${ }^{\oplus} \mathrm{PoP}$. The CpaB gene of Caulobacter crescentus is an RcpC homolog of the $A$. actinomycetemcomitans Tad protein secretion system and is considered to be an essential gene owing to its predicted function to aid in the assembly of the outer membrane complex and facilitating the extrusion of the pilus through the secretin ring (Tomich et al. 2007).

A second type of surface appendage, distinct from the (observed) pilus fibers, was present on the external surface of negatively stained CLso cells (Fig. 8). This appendage was composed of only one fiber, approximately $20 \mathrm{~nm}$ in diameter, and so is hypothesized to represent a flagellum, given its similar size and morphology to flagella described for members of the genus Rhizobium (Aizawa 2002), plant-associated bacteria classified, along with ' $\mathrm{Ca}$. Liberibacter', in the Rhizobiaceae. Rhizobium species have been shown to have both pili and peritrichous flagella (Aizawa 2002; Saad et al. 2005). By extrapolation, it is reasonable to suggest that the structures observed associated with CLso cells represent these latter two types of external appendages. In support of this possibility, genes predicted to encode regulatory and structural components of pili and flagella were identified and confirmed to be

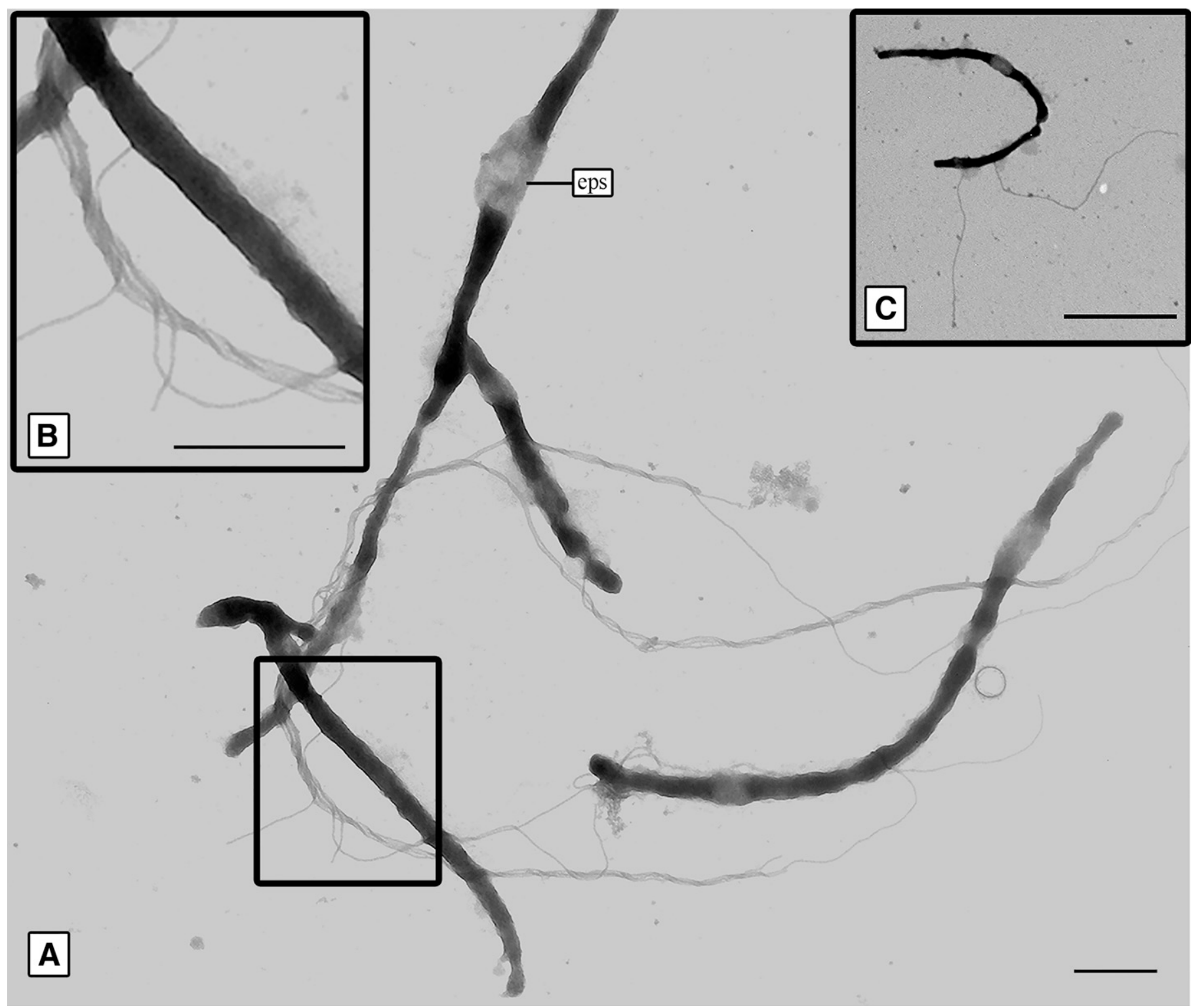

Fig. 7. Examples of CLso pili seen by transmission electron microscopy using negative staining technique. A, Interpreted to be multistranded, indicative of pili. Line $=0.5 \mu \mathrm{m}$. B, Inset from A. Line $=0.5 \mu \mathrm{m}$. C, Full length of appendages. Line $=2 \mu \mathrm{m}$. eps, electron translucent material is interpreted to be an extracellular polymeric substance, either newly formed or residual, that was present on the bacteria after dissociation from the midgut and fixation. 
present in the CLso genome sequence (Lin et al. 2011). Among these were the flagellar basal body protein (FliL), flagellar hook protein (FlgE), flagellar MS-ring protein, flagellar motor proteins, and a flagellum-specific ATP synthase. Further, the expression of all of these genes has been documented in the transcriptome of ' $\mathrm{Ca}$. Liberibacter'-infected psyllids (Fisher et al. 2014; Vyas et al. 2015). Taken together, evidence based on both the genome sequence and transcriptome, the TEM observations, and RT-PCR amplification of selected flagellum- and/or pilus-related transcripts, e.g., the flagellar motor protein A (motA) transcript, provide robust support for the production of pilus- and flagella-like external appendages by CLso. Feasibly, they are involved in invasion, adhesion, and/or motility during the CLso life cycle in the psyllid host (and vector). Thus, it appears that pili and flagella production are inherent characteristics of CLso, and that when more fully characterized, will lead to a better understanding of their role in ' $\mathrm{C}$. Liberibacter' pathogenesis in the psyllid vector, and perhaps also in the plant host.

In summary, these results provide direct, correlative evidence between in situ labeling of the CLso morphotype, biofilm formation, and the facultative production of surface appendages. Together

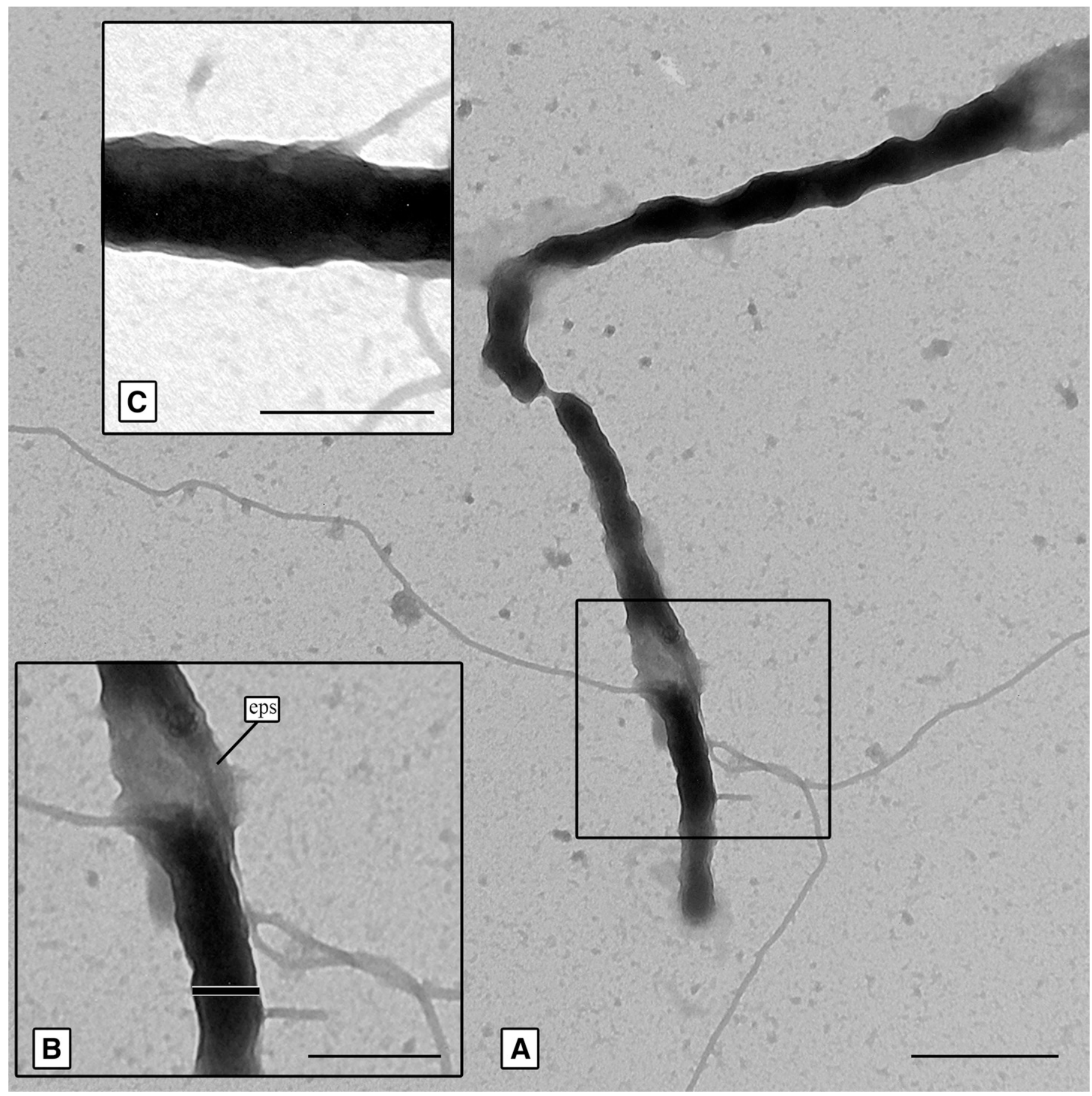

Fig. 8. Examples of flagellated CLso seen by transmission electron microscopy using negative staining technique. Stain uptake (positive staining) was more predominant. A, Bacterium was apparently in the process of dividing. Line $=0.5 \mu \mathrm{m}$. B, Inset from A. Appendages single stranded, indicative of flagella. Diametric $=$ $0.125 \mu \mathrm{m}$. Line $=0.25 \mu \mathrm{m}$. C, Close-up of another specimen. Appendages are also single stranded. Line $=0.5 \mu \mathrm{m}$. eps, electron translucent material is interpreted to be an extracellular polymeric substance, either newly formed or residual, that was present on the bacteria after dissociation from the midgut and fixation. 
these observations provide robust support for a circulative, propagative mode of CLso transmission by PoP. In this scenario the pili would be involved in adhesion leading to colonization and biofilm formation, whereas the flagella function in motility during circulation in the psyllid hemolymph and perhaps elsewhere. Thus, interference with aspects of the respective psyllid-encoded protein interactors by RNA interference could provide a strategic approach for abatement of Liberibacter infection of and circulation in the psyllid host to prevent vector acquisition and/or reduce transmission frequency to the plant host.

\section{ACKNOWLEDGMENTS}

We thank D. Carbonaro (Plant Sciences, University of Arizona) who assisted with psyllid colony maintenance and aspects of molecular assays; and E.-D. Ammar (USDA Horticultural Research Lab, Ft. Pierce, FL) and C. Alteri (Department of Microbiology and Immunology, University of Michigan Medical School, Ann Arbor) for technical consultation. This study was funded by a grant from the Florida Citrus Advanced Technology Program Project 34, Citrus Research and Development Foundation.

\section{LITERATURE CITED}

Abad, J. A., Bandla, M., French-Monar, R. D., Liefting, L. W., and Clover, G. R. G. 2009. First report of the detection of 'Candidatus Liberibacter' species in zebra chip disease-infected potato plants in the United States. Plant Dis. 93:108.

Aizawa, S.-I. 2002. Flagella. Pages 155-175 in: Molecular Medical Microbiology. M. Sussman, ed. Academic Press, San Diego, CA.

Alivizatos, A. S. 1982. Feeding behavior of the spiroplasma vectors Dalbulus maidis and Eucelidius variegatus in vivo and in vitro. Ann. Inst. Phytopathol. Benaki (N.S.) 13:128-144.

Ammar, E. D., Shatters, R. G., Jr., and Hall, D. G. 2011a. Localization of Candidatus Liberibacter asiaticus, associated with citrus huanglongbing disease, in its psyllid vector using fluorescence in situ hybridization. J. Phytopathol. 159:726-734.

Ammar, E.-D., Shatters, R. G., Jr., Lynch, C., and Hall, D. G. 2011b. Detection and relative titer of Candidatus Liberibacter asiaticus in the salivary glands and alimentary canal of Diaphorina citri (Hemiptera: Psyllidae) vector of citrus huanglongbing disease. Ann. Entomol. Soc. Am. 104:526-533.

Ariovich, D., and Garnett, H. M. 1985. Structure of the greening organism. Citrus and Subtropical Fruit J. (Dec./Jan.) 611:6-8.

Ariovich, D., and Garnett, H. M. 1989. The use of immune-gold staining techniques for detection of a bacterium associated with greening diseased citrus. Phytopathology 79:382-384.

Binder, M., Tourmente, S., Roth, J., Renaud, M., and Gehring, W. J. 1986. In situ hybridization at the electron microscope level: Localization of transcripts on ultrathin sections of Lowicryl K4M-embedded tissue using biotinylated probes and protein A-gold complexes. J. Cell Biol. 102: 1646-1653.

Bove, J. M. 2006. Huanglongbing: A destructive, newly-emerging, century-old disease of citrus. J. Plant Pathol. 88:7-37.

Brown, J. K., Rehman, M., Rogan, D., Martin, R. R., and Idris, A. M. 2010. First report of "Candidatus Liberibacter psyllaurous" (synonym "Ca. L. solanacearum") associated with 'Tomato vein-greening' and 'Tomato psyllid yellows' diseases in commercial greenhouses in Arizona. Plant Dis. 94:376.

Chen, M.-H., Miyakawa, T., and Matsui, C. 1971. Mycoplasmalike bodies associated with likubin-diseased ponkan citrus. Phytopathology 61:598.

Chen, M.-H., Miyakawa, T., and Matsui, C. 1973. Citrus-likubin pathogens in salivary glands of Diaphorina citri. Phytopathology 63:194-195.

Cooper, W. R., Sengoda, V. G., and Munyaneza, J. E. 2014. Localization of 'Candidatus Liberibacter solanacearum' (Rhizobiales: Rhizobiaceae) in Bactericera cockerelli (Hemiptera: Triozidae). Ann. Entomol. Soc. Am. 107:204-210.

Crosslin, J. M., Munyaneza, J. E., Brown, J. K., and Liefting, L. W. 2010. A history in the making: Potato zebra chip disease associated with a new psyllid-borne bacterium-A tale of striped potatoes. Online publication. doi: 10.1094/APSnetFeature-2010-0110

Davis, M. J., Mondal, S. N., Chen, H., Rogers, M. E., and Brlansky, R. H. 2008. Co-cultivation of 'Candidatus Liberibacter asiaticus' with Actinobacteria from citrus with Huanglongbing. Plant Dis. 92:1547-1550.

Fisher, T. W., Vyas, M., He, R., Nelson, W., Cicero, J. M., Willer, M., and Brown, J. K. 2014. Comparison of potato and Asian citrus psyllid adult and nymph transcriptomes identified vector transcripts with potential involvement in circulative, propagative Liberibacter transmission. Pathogens 3:875-907.
Fraser, L. R., Singh, D., Capoor, S. P., and Nariani, T. K. 1966. Greening virus, the likely cause of citrus dieback in India. FAO Plant Prot. Bull. 14: 127-130.

Garnett, H. M. 1985. Isolation of the greening organism. Citrus Subtrop. Fruit J. 611:4-5.

Garnier, M., and Bové, J. M. 1983. Transmission of the organism associated with Citrus greening disease from sweet orange to periwinkle by dodder. Phytopathology 73:1358-1363.

Ghanim, M., Brumin, M., and Popovski, S. 2009. A simple, rapid and inexpensive method for localization of Tomato yellow leaf curl virus and Potato leafroll virus in plant and insect vectors. J. Virol. Methods 159: 311-314.

Ghosh, S. K., Raychaudhuri, S. P., Chenulu, V. V., and Varma, A. 1975. Isolation, cultivation and characterization of mycoplasma-like organisms from plants. Proc. Indian Natl. Sci. Acad. B 41:362-366.

Ghosh, S. K., Raychaudhuri, S. P., Varma, A., and Nariani, T. K. 1971. Isolation and culture of mycoplasma associated with citrus greening disease. Curr. Sci. 11:299-300.

Gottwald, T. R., da Graça, J. V., and Bassanezi, R. B. 2007. Citrus Huanglongbing: The pathogen and its impact. Online publication. Plant Health Progress. doi:10.1094/PHP-2007-0906-01-RV

Haapalainen, M. 2014. Biology and epidemics of Candidatus Liberibacter species, psyllid-transmitted plant-pathogenic bacteria. Ann. Appl. Biol. 165:172-198.

Hansen, A. K., Trumble, J. T., Stouthamer, R., and Paine, T. D. 2008. A new Huanglongbing species, "Candidatus Liberibacter psyllaurous," found to infect tomato and potato, is vectored by the psyllid Bactericera cockerelli (Sulc). Appl. Environ. Microbiol. 74:5862-5865.

Hilf, M. E., Sims, K. R., Folimonova, S. Y., and Achor, D. S. 2013. Visualization of 'Candidatus Liberibacter asiaticus' cells in the vascular bundle of citrus seed coats with fluorescence in situ hybridization and transmission electron microscopy. Phytopathology 103:545-554.

Jagoueix, S., Bové, J. M., and Garnier, M. 1996. PCR detection of the two 'Candidatus' liberobacter species associated with greening disease of citrus. Mol. Cell. Probes 10:43-50.

Javelle, M., Marco, C. F., and Timmermans, M. 2011. In situ hybridization for the precise localization of transcripts in plants. J. Vis. Exp. 57: e3328.

Kanehisa, M., Goto, S., Kawashima, S., and Nakaya, A. 2002. The KEGG databases at GenomeNet. Nucleic Acids Res. 30:42-46.

Laflèche, D., and Bové, J. M. 1970. Structures de type mycoplasme dans les feuilles d'orangers atteints de la maladie du greening. C. R. Acad. Sci. Ser. D 270:455-465.

Liefting, L. W., Perez-Egusquiza, Z. C., Clover, G. R. G., and Anderson, J. A. D. 2008. A new 'Candidatus Liberibacter' species in Solanum tuberosum in New Zealand. Plant Dis. 92:1474.

Liefting, L. W., Weir, B. S., Pennycook, S. R., and Clover, G. R. G. 2009. 'Candidatus Liberibacter solanacearum', associated with plants in the family Solanaceae. Int. J. Syst. Evol. Microbiol. 59:2274-2276.

Lin, H., Lou, B., Glynn, J. M., Doddapaneni, H., Civerolo, E. L., Chen, C., Duan, Y., Zhou, L., and Vahling, C. M. 2011. The complete genome sequence of 'Candidatus Liberibacter solanacearum', the bacterium associated with potato zebra chip disease. PLoS ONE 6:e19135.

Mann, R. S., Pelz-Stelinski, K., Hermann, S. L., Tiwari, S., and Stelinski, L. L. 2011. Sexual transmission of a plant pathogenic bacterium, Candidatus Liberibacter asiaticus, between conspecific insect vectors during mating. PLoS ONE 6:e29197.

Massonie, G., Garnier, M., and Bove, J. M. 1976. Transmission of Indian citrus decline by Trioza erytreae (Del Guercio), the vector of South African greening. Pages 18-20 in: Proceedings of the Seventh Conference of the International Organization of Citrus Virologists. E. C. Calavan, ed. Riverside, CA.

Moll, J. N., and Martin, M. M. 1973. Electron microscope evidence that citrus psylla (Trioza erytreae) is a vector of greening disease in South African. Phytophylactica 5:41-44.

Munyaneza, J. E., Fisher, T. W., Sengoda, V. G., Garczynski, S. F., Nissinen, A., and Lemmetty, A. 2010. First report of "Candidatus Liberibacter solanacearum" associated with psyllid-affected carrots in Europe. Plant Dis. 94:639.

Nachappa, P., Levy, J., Pierson, E., and Tamborindeguy, C. 2011. Diversity of endosymbionts in the potato psyllid, Bactericera cockerelli (Hemiptera: Triozidae), vector of zebra chip disease of potato. Curr. Microbiol. 62: 1510-1520.

Nachappa, P., Shapiro, A. A., and Tamborindeguy, C. 2012. Effect of 'Candidatus Liberibacter solanacearum' on fitness of its insect vector, Bactericera cockerelli (Hemiptera: Triozidae), on tomato. Phytopathology 102: 41-46.

Nelson, W. R., Sengoda, V. G., Alfaro-Fernandez, A. O., Font, M. I., Crosslin, J. M., and Munyaneza, J. E. 2013. A new haplotype of "Candidatus 
Liberibacter solanacearum" identified in the Mediterranean region. Eur. J. Plant Pathol. 135:633-639.

Nissinen, A. I., Haapalainen, M., Jauhiainen, L., Lindman, M., and Pirhonen, M. 2014. Different symptoms in carrots caused by male and female carrot psyllid feeding and infection by 'Candidatus Liberibacter solanacearum'. Plant Pathol. 63:812-820.

Parker, J. K., Wisotsky, S.R., Johnson, E. G., Hijaz, F. M., Killiny, N., Hilf, M. E., and De La Fuente, L. 2014. Viability of 'Candidatus Liberibacter asiaticus' prolonged by addition of citrus juice to culture medium. Phytopathology 104:15-26.

Rehman, M., Melgar, J., Rivera, C. J. M., Idris, A. M., and Brown, J. K. 2010. First report of "Candidatus Liberibacter psyllaurous" or " $\mathrm{Ca}$. Liberibacter solanacearum" associated with severe foliar chlorosis, curling, and necrosis and tuber discoloration of potato plants in Honduras. Plant Dis. 94:376.

Saad, M. M., Kobayashi, H., Marie, C., Brown, I. R., Mansfeld, J. W., Broughton, W. J., and Deakin, W. J. 2005. NopB, a Type III secreted protein of Rhizobium sp. strain NGR234, is associated with pilus-like surface appendages. J. Bacteriol. 187:1173-1181.

Saha S., Hunter, W. B., Reese J., Morgan J. K., Marutani-Hert M., Huang, H., and Lindeberg, M. 2012. Survey of endosymbionts in the Diaphorina citri metagenome and assembly of a Wolbachia wDi draft genome. PLoS ONE 7:e50067.

Sambrook, J., Fritsch, E. F., and Maniatis, T. 1989. Molecular Cloning: A Laboratory Manual, 2nd Ed. Cold Spring Harbor Laboratory, Cold Spring Harbor, New York.

Sechler, A., Schuenzel, E. L., Cooke, P., Donnua, S., Thaveechai, N., Postnikova, E., Stone, A. L., Schneider, W. L., Damsteegt, V. D., and Schaad, N. W. 2009. Cultivation of 'Candidatus Liberibacter asiaticus', ' $\mathrm{Ca}$. L. africanus', and ' $\mathrm{Ca}$. L. americanus' associated with Huanglongbing. Phytopathology 99:480-486.

Secor, G. A., Rivera, V. V., Abad, J. A., Lee, I.-M., Clover, G. R. G., Liefting, L. W., Li, X., and De Boer, S. H. 2009. Association of 'Candidatus Liberibacter solanacearum' with zebra chip disease of potato established by graft and psyllid transmission, electron microscopy, and PCR. Plant Dis. 93:574-583.

Sengoda, V. G., Cooper, W. R., Swisher, K. D., Henne, D. C., and Munyaneza, J. E. 2014. Latent period and transmission of "Candidatus Liberibacter solanacearum" by the potato psyllid Bactericera cockerelli (Hemiptera: Triozidae). PLoS ONE 9:e93475.

Shokrollah, H., Abdullah, T. L., Sijam, K., and Abdullah, S. N. A. 2010. Ultrastructures of Candidatus Liberibacter asiaticus and its damage in huanglongbing (HLB) infected citrus. Afr. J. Biotechnol. 9:5897-5901.
Sodhi, S. S., and Dhillion, S. S. 1973. Isolation and characterization of mycoplasms like organisms associated with citrus greening disease. Indian J. Microbiol. 13:13-16.

Sodhi, S. S., Dhillon, S. S., Jeyarajan, R., and Cheema, S. S. 1975. Mycoplasma-like organism associated with citrus greening disease. Proc. Indian Natl. Sci. Acad. B 41:386-389.

Swisher, K. D., Munyaneza, J. E., and Crosslin, J. M. 2012. High resolution melting analysis of the cytochrome oxidase I gene identifies three haplotypes of the potato psyllid in the United States. Environ. Entomol. 41: 1019-1028.

Tahzima, R., Maes, M., Achbani, E. H., Swisher, K. D., Munyaneza, J. E., and De Jonghe, K. 2014. First report of 'Candidatus Liberibacter solanacearum' on carrot in Africa. Plant Dis. 98:1426.

Teresani, G. R., Bertolini, E., Alfaro-Fernández, A., Martínez, C., Tanaka, F. A. O., Kitajima, E. W., Roselló, M., Sanjuán, S., Ferrándiz, J. C., López, M. M., Cambra, M., and Font, M. I. 2014. Association of 'Candidatus Liberibacter solanacearum' with a vegetative disorder of celery in Spain and development of a real-time PCR method for its detection. Phytopathology 104:804-811.

Tomich, M., Planet, P. J., and Figurski, D. H. 2007. The tad locus: postcards from the widespread colonization island. Natl. Rev. 5:363-375.

Ullman, D. E., and McLean, D. L. 1986. Anterior alimentary canal of the pear psylla, Psylla pyricola Foerster (Homoptera, Psyllidae). J. Morphol. 189: 89-98.

Vyas, M., Fisher, T. W., He, R., Nelson, W., Yin, G., Cicero, J. M., Willer, M., Kim, R., Kramer, R., May, G. A., Crow, J. A., Soderlund, C. A., Gang, D. R., and Brown, J. K. 2015. Asian citrus psyllid expression profiles suggest Candidatus Liberibacter asiaticus-mediated alteration of adult nutrition and metabolism, and of nymphal development and immunity. PLoS ONE 10:e0130328.

Wang, N., and Trivedi, P. 2013. Citrus huanglongbing: A newly relevant disease presents unprecedented challenges. Phytopathology 103:652-665.

Yan, Q., Sreedharan, A., Wei, S., Wang, J., Pelz-Stelinski, K., Folimonova, S., and Wang, N. 2013. Global gene expression changes in Candidatus Liberibacter asiaticus during the transmission in distinct hosts between plant and insect. Mol. Plant Pathol. 14:391-404.

Zatakia, H. M., Nelson, C. E., Syed, U. J., and Scharf, B. E. 2014. ExpR coordinates the expression of symbiotically important, bundle-forming Flp pili with quorum sensing in Sinorhizobium meliloti. Appl. Environ. Microbiol. 80:2429-2439. 